\title{
Qualifying thirst distress in the acute hospital setting - validation of a patient-reported outcome measure.
}

Follow this and additional works at: https://www.journal.acorn.org.au/jpn

Part of the Anesthesiology Commons, Dietetics and Clinical Nutrition Commons, and the Perioperative, Operating Room and Surgical Nursing Commons

(c) (7)

This work is licensed under a Creative Commons Attribution 4.0 License.

\section{Recommended Citation}

Carey, Sharon Dr; Waller, Jacob Dr; Wang, Lucy Yueming Ms; and Ferrie, Suzie Dr (2021) "Qualifying thirst distress in the acute hospital setting - validation of a patient-reported outcome measure.," Journal of Perioperative Nursing: Vol. 34 : Iss. 4 , Article 6.

Available at: https://doi.org/10.26550/2209-1092.1156

https://www.journal.acorn.org.au/jpn/vol34/iss4/6

This Article is brought to you for free and open access by Journal of Perioperative Nursing. It has been accepted for inclusion in Journal of Perioperative Nursing by an authorized editor of Journal of Perioperative Nursing. 
Qualifying thirst distress in the acute hospital setting - validation of a patientreported outcome measure.

\section{Cover Page Footnote}

Acknowledgements: Sharon Carey received a Medical Research Future Fund Translating Research Into Practice Fellowship to conduct this research. 


\section{Authors}

Dr Sharon Carey

PhD

Royal Prince Alfred Hospital, University of Sydney

Dr Jacob Waller

MBBS, BMedSC

Royal Prince Alfred Hospital

Lucy Yueming Wang

MND

University of Sydney

Dr Suzie Ferrie

PhD

Royal Prince Alfred Hospital, University of Sydney

\section{Corresponding author}

Dr Sharon Carey

PhD

Royal Prince Alfred Hospital,

University of Sydney

sharon.carey1@health.nsw.gov.au

\title{
Qualifying thirst distress in the acute hospital setting - validation of a patient-reported outcome measure
}

\begin{abstract}
Objective: This study aims to examine validity and sensitivity of two visual analogue scales (VASS), measuring thirst intensity and thirst distress, and compare them with a validated thirst discomfort scale (TDS).
\end{abstract}

Methods: This is a non-interventional, prospective and cross-sectional study. Researchers recruited 161 patients from an acute surgical hospital, who were identified at time of interaction as fasting. Data was collected using a questionnaire, which included the TDS. Criterion validity and construct validity was tested for the two VASs. Sensitivity was assessed based on the amount of time fasting from solid foods or fluids.

Results: Results showed the VAS for thirst intensity, the VAS for thirst distress and the average of the VAS scores correlated with the TDS ( $\rho=0.66,0.81$ and 0.72 respectively, all $p<0.001$ ).

Conclusions: Our findings suggest that the VAS is a valid and sensitive patientreported outcome measure for thirst distress in fasting patients.

Keywords: fasting, thirst distress, thirst discomfort scale, visual analogue scale.

\section{Background}

Fasting is often required before investigations and procedures needing sedation or anesthesia'. There is strong (Level A) evidence to support reduced fasting times, allowing the safe consumption of solids up to six hours, and clear fluids up to two hours prior to a procedure requiring anaesthesia'. These recommendations have been adopted within local governing organisations ${ }^{2}$ but implementation into clinical practice has been slow. The prevalence of prolonged fasting, beyond six hours for solids and two hours for fluids, remains high within the hospital setting ${ }^{3}$. It has been identified that complex historical, cultural and systemic barriers within the hospital system are the main obstacles to implementing evidence-based fasting practices.
A medical system where junior doctors and nurses feel unable to challenge surgeon instructions and where there is lack of connectivity between surgical, ward and diet ordering systems as well as a tradition of 'fasting from midnight' means that the majority of patients will be asked to fast for prolonged periods 4 . Similarly, repeated and extended fasting is experienced when procedures are rescheduled or cancelled ${ }^{3,5,6}$. Current data shows fasting for longer than recommended times not only leads to physiological discomfort, such as thirst, dry mouth and dehydration, but also impacts a patient's psychological status causing irritability and anxiety ${ }^{6-8}$. Previous qualitative research has shown high levels of distress in patients fasted for extended periods of time. This is likely due to the physiological response but also due 
to the emotional significance of food and a consequent lack of autonomy ${ }^{8}$. The hospital system leaves patients with little internal control, where food is often seen as one of the few aspects of care over which patients and families have control. This relationship with food is significant as food and feeding is symbolic of caregiving and return to health ${ }^{8}$.

Moreover, the detrimental changes in physiological function due to prolonged fasting can be seen within 24 hours through increased insulin resistance and reduced muscle function?. Extended or repeated fasting can further lead to hospitalacquired malnutrition ${ }^{10}$. The catabolic sequelae related to malnutrition negatively impact risk of infection ${ }^{11}$, complications rates ${ }^{12}$ and length of stay ${ }^{13}$ while overall malnutrition increases the risk of mortality ${ }^{13}$.

Thirst is a common subjective symptom among fasting patients driven by physiological responses to hypovolaemia ${ }^{14}$. Thirst is exacerbated by extended peri-procedural fasting together with increased anxiety about the upcoming procedure ${ }^{15,16}$. The presence of thirst has been shown to have a negative impact on quality of life ${ }^{17}$ and may detract from the patient's experience. Previous qualitative research indicates that fasted participants describe overwhelming thirst and dry mouth as the most difficult aspect of fasting ${ }^{8}$. As such, it is important to be able to measure thirst to assess the level of fasting-related distress and implement management strategies to reduce thirst-related distress. This can be done by using a valid patient-reported outcome measure (PROM). PROMs provide the patient's perspective by recording feedback directly without input from other health professionals ${ }^{1819}$. Health care systems are beginning to recognise the importance of patient-reported outcomes as a measure of quality of care and an integral part of clinical governance ${ }^{20}$.

One research team from Brazil developed and validated a thirst discomfort scale (TDS) determining perioperative thirst discomfort based on a sample of 70 patients ${ }^{15}$. The TDS involves quantifying seven aspects of thirst on a three-point Likert scale (Table 1). It has been used to measure change in thirst discomfort following implementation of interventions aimed to reduce thirst in heart failure ${ }^{21}$ and haemodialysis ${ }^{22}$ populations. This tool is useful within research but may have limited use in a busy hospital setting as a part of usual care. The length of the questionnaire can make data collection and analysis time consuming in the clinical setting and may be seen as a perceived barrier to implementing it as a part of a pre-operative assessment tool. Another study by Puntillo et al. ${ }^{16}$ also measured thirst intensity and distress in a randomised study assessing the impact of interventions to improve mouth dryness and distress in intensive care patients undergoing procedures. Puntillo et al. ${ }^{16}$ used two visual analogue scales (VASs) measuring intensity and distress related to thirst prior to fasting for procedures and postrandomisation based on intervention versus control ${ }^{16}$. While the VAS has been validated to measure different outcomes including quality of life ${ }^{23}$ and pain ${ }^{24}$, specific use of VASs for thirst intensity and thirst distress has not been validated.

\section{Aim}

The aim of the current study is to investigate the criterion validity, construct validity and sensitivity of the two VAS questions relating to thirst intensity and thirst distress (as shown in Table 1) in a cohort of fasting adult inpatients at a quaternary referral hospital in Sydney,
Australia, and validate it against the already validated TDS.

It is hypothesised that the two VAS questions will correlate with the TDS; that the two VAS questions will correlate with each other; and that fasting-related distress will be proportional to the length of time spent fasting.

\section{Methods}

\section{Study design}

The study is a non-interventional prospective cross-sectional study applied to a random sample of adult inpatients required to fast. The study was conducted within a quaternary hospital in Sydney, Australia, across surgical and non-surgical wards during a six-week period from August to October 2019. The study was approved by the Ethics Review Committee of Sydney Local Health District, Royal Prince Alfred Hospital (Protocol Number X19-0158).

\section{Participants}

Patients were deemed eligible for inclusion if they met the following inclusion criteria: more than 18 years old, fasting at the time of interaction and able to communicate in English. Patients were excluded if there was a history of dementia, cognitive impairment or unconsciousness, contact/isolation precautions, clinical instability, a diagnosed eating disorder or implemented nutritional support.

Initial study recruitment was undertaken by the dietitian or dietitian assistant seeing the patient during routine malnutrition screening and/or screening for potential implementation of nutrition interventions. Where patients were happy to be involved, one member of the research team (LY) approached the patient for written consent. 
Table 1: Thirst distress scale (TDS) and visual analogue score (VAS) questions

\begin{tabular}{|c|c|c|}
\hline Tool & Aspect to be quantified / questions & Ranking scale \\
\hline Thirst distress scale (TDS) & $\begin{array}{l}\text { 1. My mouth is dry } \\
\text { 2. My lips are dry } \\
\text { 3. My tongue is thick } \\
\text { 4. My saliva is thick } \\
\text { 5. My throat is dry } \\
\text { 6. I have a bad taste in my mouth } \\
\text { 7. I want to drink water }\end{array}$ & $\begin{array}{l}0=\text { not bothered } \\
1=\text { slightly bothered } \\
2=\text { very bothered }\end{array}$ \\
\hline \multirow[t]{2}{*}{ Visual analogue scales (VASs) } & $\begin{array}{l}\text { How intense is your thirst at the } \\
\text { moment? }\end{array}$ & $\begin{array}{l}0-10 \text { where } 0 \text { means not thirsty at all } \\
\text { and } 10 \text { means intense thirst. }\end{array}$ \\
\hline & $\begin{array}{l}\text { How distressing (or bothersome) is your } \\
\text { thirst is at the moment? }\end{array}$ & $\begin{array}{l}0-10 \text { where } 0 \text { means not distressed at all } \\
\text { and } 10 \text { means extreme distress. }\end{array}$ \\
\hline
\end{tabular}

\section{Data collection}

The questionnaire consisted of eleven questions. Two questions asked patients how long they had been fasting from solids and fluids, seven questions were directly from the TDS validated too $\mathrm{l}^{15}$, and the two VAS questions assessed the thirst intensity and thirst distress levels. Additional information was collected by the recruiting research team member (LY), noting if the patient was receiving intravenous (IV) fluids at the time of the visit. No demographic, disease-related or procedure-related information was collected and all data was nonidentifiable.

\section{Measurements}

The length of fasting time was reported in hours. The seven items of the TDS were rated on a threepoint Likert scale, ranging from 'not bothered' (score of 0) to 'very bothered' (score of 2). The total score ranged from 0 to 14 , with higher scores indicating a more intense thirst-related discomfort as per the validated too ${ }^{15}$. For the VAS questions, patients were asked to rate their level of thirst intensity and level of distress related to their thirst on a scale where the left end $(0 \mathrm{~cm})$ indicated no thirst at all and the right end $(10 \mathrm{~cm})$ indicated worst possible thirst. The VAS scores were reported as the thirst intensity score and the thirst distress score; an average VAS score, which was the average of the thirst intensity and the thirst distress scores, was also calculated.

\section{Data analysis}

All data were entered directly into RedCap and assessed using SPSS (version 25, SPSS Inc., Chicago, Illinois, USA). The Kolmogorov-Smirnov test was used to assess normality of data; variables that didn't follow a normal distribution were demonstrated as median with interquartile range (IQR).

Criterion validity of the two VASs was measured by calculating the Spearman correlation coefficient $(\rho)$ for the thirst intensity score and the TDS total score, the $\rho$ for the thirst distress score and the TDS total score, and the $\rho$ for the average VAS score and the TDS total score. In terms of construct validity, Spearman correlation was used again to assess the relationship between the two VAS questions: thirst intensity and thirst distress.
To test sensitivity, participants were separated into four groups based on quartiles of solid-fasting time and another four groups based on quartiles of fluid-fasting time. Comparisons of raw data were made across the four quartiles for both solid-fasting and fluid-fasting groups using the Kruskal-Wallis test, and two quartiles using the Mann-Whitney U. The Spearman's correlation was used to determine the relationship between fasting time and the TDS total score, the thirst intensity score, the thirst distress score and average VAS score. Additionally, a MannWhitney $U$ test was used to test the differences in scores and the length of fasting time between patients with or without IV fluids. A p-value of $<0.05$ was considered as significant.

\section{Results}

\section{Sample characteristics}

The study included 161 participants, with the majority of patients coming from the surgical wards. The median (and IQR) time fasting for solids and clear fluid were 16 (12) and 10 (13) hours, respectively. A total of 88 (54.66\%) participants were receiving IV fluids. 


\section{Criterion validity}

Median (IQR) scores from the TDS and the VAS questions for all patients are displayed in Table 2. The scores generated from the TDS were used as the reference to assess the criterion validity of the VAS. A strong positive, significant correlation was found between the VAS measuring thirst intensity and the TDS $(\rho=0.66$, $p<0.001)$, between the VAS measuring thirst distress and the TDS $(\rho=0.71$, $p<0.001)$, and between the average VAS and the TDS $(\rho=0.72, p<0.001)$.

\section{Construct validity}

In terms of construct validity, a very strong positive and significant correlation was registered between the two VAS questions ( $\rho=0.84$, $p<0.001$ ). Patients with a greater thirst intensity score had a significantly higher thirst distress score.

\section{Sensitivity}

In order to investigate the sensitivity of the VAS questions and compare it with the TDS, patients were classified into four groups according to their reported hours of fasting from solid foods and another four groups according to their reported hours of fasting from fluids. The fasting from solids groups (and the number of hours fasting) were: Group 1 (<12 hours), Group 2 (12-15.5 hours), Group 3 (16-23 hours), Group 4 (> 23 hours). The fasting from liquids groups (and the number of hours fasting) were: Group A ( $<2$ hours), Group B (2-9.5 hours), Group C (10-14.5 hours), Group D (> 14.5 hours). Timeframes were determined to provide about equal numbers of participants in each of the groups. The median scores of the TDS, the thirst intensity VAS, the thirst distress VAS and the average VAS of patients in solid-fasting groups and fluidfasting groups are displayed in Table 2 and Table 3, respectively.

The median TDS total score, the median VAS scores for thirst intensity and thirst distress and the average VAS score significantly correlated with the amount of time patients were fasting from solids $(\rho=0.331$, $0.421,0.390$ and 0.422 , respectively, all $p<0.001)$. The Kruskal-Wallis test indicated that the scores for all the solid-fasting groups were significantly different (all $p<0.001$ ). As shown in Table 2, patients with shorter solidfasting times had overall lower scores in the TDS, the VAS for thirst intensity and the average VAS compared to groups with longer solid-fasting time. Patients in Group 4 fasting for more than 23 hours were found to score significantly higher in all scores than patients in Group 1 who fasted for less than 16 hours ( $p<0.001)$. Statistical significance was also observed in all scores between Group 2 and Group $4(p<0.001)$.

For groups that were categorised based on the time fasting from fluids, the length of fast was significantly correlated with the thirst intensity score and the average VAS score ( $\rho=0.158$ and 0.173 , respectively, both $\mathrm{p}<0.05)$. However, there was no significant statistical difference between the four groups in all the scores (TDS $\rho=0.058$, intensity VAS $\rho=0.144$, distress VAS $\rho=0.181$; average VAS $\rho=0.176)$, although a trend was observed for higher thirst distress with increasing fasting time (see Table 3). Apart from the thirst distress score, group A had higher median

Table 2: Median scores and statistical analysis of the differences in scores of the thirst discomfort scale (TDS) and the visual analogue scales (VASs) in solid-fasting groups

\begin{tabular}{|c|c|c|c|c|c|}
\hline & $\begin{array}{l}\text { Group } 1 \\
(n=39)\end{array}$ & $\begin{array}{c}\text { Group } 2 \\
(n=40)\end{array}$ & $\begin{array}{c}\text { Group } 3 \\
(n=37)\end{array}$ & $\begin{array}{c}\text { Group } 4 \\
(n=45)\end{array}$ & $\begin{array}{l}\text { Total } \\
(n=161)\end{array}$ \\
\hline TDS total score & $3.00(8.00)$ & $4.00(5.00)$ & $6.00(7.00)$ & $9.00(6.00)$ & $6.00(7.00)$ \\
\hline Significant difference with & Group 4 & Group 4 & & & \\
\hline Thirst intensity VAS score & $4.00(3.90)$ & $4.60(5.10)$ & $6.00(3.60)$ & $6.40(3.20)$ & $5.00(4.20)$ \\
\hline Significant difference with & $\begin{array}{l}\text { Group } 3 \\
\text { Group } 4\end{array}$ & $\begin{array}{l}\text { Group } 3 \\
\text { Group } 4\end{array}$ & & & \\
\hline Thirst distress VAS score & $3.00(5.00)$ & $2.65(4.60)$ & $5.00(3.80)$ & $7.00(4.70)$ & $4.50(5.30)$ \\
\hline Significant difference with & $\begin{array}{l}\text { Group } 3 \\
\text { Group } 4\end{array}$ & $\begin{array}{l}\text { Group } 3 \\
\text { Group } 4\end{array}$ & Group 4 & & \\
\hline Average VAS score & $3.50(4.00)$ & $3.68(4.69)$ & $5.00(2.88)$ & $7.00(4.00)$ & $5.00(4.88)$ \\
\hline Significant difference with & $\begin{array}{l}\text { Group } 3 \\
\text { Group } 4\end{array}$ & $\begin{array}{l}\text { Group } 3 \\
\text { Group } 4\end{array}$ & & & \\
\hline
\end{tabular}


Table 3: Median scores and statistical analysis of the differences in scores of the thirst discomfort scale (TDS) and the visual analogue scales (VASs) in fluid-fasting groups

\begin{tabular}{|l|c|c|c|c|c|}
\hline & $\begin{array}{c}\text { Group A } \\
(n=35)\end{array}$ & $\begin{array}{c}\text { Group B } \\
(n=39)\end{array}$ & $\begin{array}{c}\text { Group C } \\
(n=45)\end{array}$ & $\begin{array}{c}\text { Group D } \\
(n=42)\end{array}$ & $\begin{array}{c}\text { Total } \\
(n=161)\end{array}$ \\
\hline TDS total score & $7.00(7.00)$ & $5.00(7.00)$ & $4.00(7.00)$ & $8.00(6.00)$ & $6.00(7.00)$ \\
\hline Significant difference with & & & Group D & & \\
\hline Thirst intensity VAS score & $5.00(5.00)$ & $4.90(3.70)$ & $5.90(4.20)$ & $6.20(3.10)$ & $5.00(4.2)$ \\
\hline Significant difference with & & Group D & & & \\
\hline Thirst distress VAS score & $3.10(5.30)$ & $4.00(5.50)$ & $5.00(4.60)$ & $5.00(4.40)$ & $4.50(5.3)$ \\
\hline Significant difference with & & Group D & & & \\
\hline Average VAS score & $4.10(5.25)$ & $3.50(3.85)$ & $5.00(4.13)$ & $5.43(3.61)$ & $4.88)$ \\
\hline Significant difference with & & Group D & & & \\
\hline
\end{tabular}

scores than group B (seeTable 3). On the other hand, although group A patients had lower median scores for the TDS, the thirst intensity VAS, the thirst distress VAS and average VAS (7.00, 5.00, 3.10 and 4.10, respectively) than those for patients in group $D$ (8.00, 5.43, 6.20 and 5.00, respectively), no significant differences were found between these two groups for all the scores ( $p=0.541,0.125,0.150$ and 0.135 , respectively). Instead, a significant difference was observed between Group B and Group D for all VAS scores, and between Group C and Group D for the TDS total score.

\section{IV fluid therapy}

The 161 patients in the study were also classified into two groups according to whether or not they received IV fluid therapy. Median fasting time and median scores of all measurements broken down by IV fluid status are presented in Table 4. The Mann-Whiney $\mathrm{U}$ test indicated significant differences in time spent fasting and all scores between the two groups; however, this result was weaker for the TDS total score. Overall, patients receiving IV fluids had longer median fasting time and higher scores in the TDS and the VAS questions.

\section{Discussion}

To our knowledge, this is the first study validating a VAS for thirst intensity and thirst distress from a patient's perspective. This study demonstrates that the two VASs had acceptable criterion and construct validity in evaluating thirst intensity and thirst distress and were comparable to the TDS. Results show that the VAS questions were sensitive enough to detect thirst intensity and thirst distress dependent on the amount of time fasting from solid food. However, this finding didn't apply to the same cohort of patients

Table 4: Median values and statistical analysis of the differences in solid and fluid fasting times and scores of the thirst discomfort scale (TDS) and the visual analogue scales (VASs) according to IV fluid status

\begin{tabular}{|l|c|c|c|c|}
\hline IV fluids status & $\begin{array}{c}\text { With IV fluids } \\
(\mathrm{n}=73)\end{array}$ & $\begin{array}{c}\text { Without IV fluids } \\
(\mathrm{n}=88)\end{array}$ & $\begin{array}{c}\text { Total } \\
(\mathrm{n}=161)\end{array}$ & $\mathrm{P}^{*}$ \\
\hline Time spent on fasting from solid food & $23.00(44.75)$ & $14.00(9.00)$ & $16.00(12.00)$ & $\mathrm{P}<0.001$ \\
\hline Time spent on fasting from fluids & $12.50(16.00)$ & $6.50(11.00)$ & $10.00(13.00)$ & $\mathrm{P}<0.01$ \\
\hline TDS total score & $7.00(6.00)$ & $5.00(7.00)$ & $6.00(7.00)$ & $\mathrm{P}<0.05$ \\
\hline Thirst intensity VAS score & $6.00(3.90)$ & $5.00(4.90)$ & $5.00(4.2)$ & $\mathrm{P}<0.01$ \\
\hline Thirst distress VAS score & $5.00(5.50)$ & $3.85(5.00)$ & $4.50(5.3)$ & $\mathrm{P}<0.01$ \\
\hline Average VAS score & $5.00(4.32)$ & $4.58(4.50)$ & $5.00(4.88)$ & $\mathrm{P}<0.01$ \\
\hline
\end{tabular}

*Differences between with and without IV fluids were assessed using the nonparametric Mann-Whitney U test 
when assessed against the amount of time fasting from fluids.

Hence, the criterion validity of the two VAS questions was supported by their positive and significant correlations with the validated TDS. In terms of construct validity, as hypothesised, the thirst distress VAS showed strong significant correlation with the thirst intensity VAS. Like previous studies this demonstrates that as thirst intensity increases so does thirst distress $22,25,26$. The two VAS questions yielded acceptable levels of construct validity in this patient population.

In terms of sensitivity, the VAS questions have been shown to perform better than the TDS in groups categorised according to the length of time fasting from solids. Similar to data reported by Tosun et al. ${ }^{27}$ scores for thirst intensity and thirst distress were associated with the amount of time spent fasting from solids. As such, patients' thirst intensity and thirst distress levels increased with increased length of fasting. Despite both tools showing acceptable sensitivity in solid-fasting, there was no demonstrable score differences between fluid-fasting groups. One possible explanation for this is a degree of ambiguity around the question 'When was the last time you had something to drink?'. Some patients were allowed to receive sips of water for comfort or water with medications during their fast and may regard this as 'something to drink'. This could result in underreporting of fluid-fasting times while still demonstrating thirst distress scores associated with a much longer fast. Study design to address this, and further patient education, may be useful in future studies in this area.

IV fluid therapy is often prescribed to prevent or relieve dehydration in fasting patients ${ }^{28}$. Patients undergoing IV fluid therapy demonstrated greater median scores in both TDS and VAS but were also subjected to longer fasting periods. This finding suggests that IV fluid therapy alone does not effectively reduce perceived thirst and its associated distress. Within our cohort this finding is potentially confounded by a selection bias such that patients receiving IV fluids were also undertaking longer fasts. Despite this, it should be considered that patients having shorter fasting times may also benefit from IV fluids to reduce both thirst and distress levels. Holte and Kehlet demonstrated the benefits of IV fluid therapy in relieving symptoms of dehydration, including light-headedness and fatigue, but found that oral fluid therapy is more effective in the relief of perceived thirst ${ }^{29}$. This suggests that it is important to address both physiological and psychological responses to fasting in order to improve patient comfort. Foremost should be implementation of fasting guidelines to allow clear fluids up to two hours prior to surgery, procedures and tests requiring anaesthesia. Where fasting cannot be prevented, thirst interventions such as regular mouth care, oral swabs, ice cubes and lip moisturiser should be considered together with IV hydration to help reduce thirst-associated discomfort and improve patient reported outcomes ${ }^{16}$.

It has been demonstrated that there is a direct correlation between patient satisfaction and their perception of receiving high-quality care $^{30}$. It has also been shown that, for patients, thirst and dehydration are the most distressing aspects of fasting ${ }^{8}$. Thus, it is necessary in the clinical setting to have the ability to objectively quantify levels of thirst intensity and thirst distress in fasting patients in order to improve their hospitalisation experience and quality of life. To date, the TDS has provided a relatively simple tool for thirst distress evaluation; however, this tool can be time consuming and confusing for some patients, limiting its use as a quick evaluation tool of thirst-related interventions. The VAS allows patients to visually represent their feelings more precisely on a linear scale, promoting objectivity ${ }^{31}$. Recent data describes the importance of identifying thirst distress to enable the implementation of best practice fasting guidelines ${ }^{4}$. The current study demonstrates the VASs to be both sensitive and specific in the objective measurement of thirst and its associated distress. This allows early recognition of fastingassociated distress and has the ability to help practitioners prescribe fasting protocols in line with patientcentred care and current guidelines. The ability of the VASs to provide rapid and accurate assessment of patient-reported thirst distress means clinical departments should consider implementing it into everyday practice to provide feedback on prolonged fasting and ensure timely thirst intervention, ultimately improving patient-reported outcomes.

\section{Limitations}

This study is limited by a lack of demographic and clinical data, which could contribute to sampling bias. As such it is difficult to comment on the application of these findings in specific cohorts. Further studies should seek to quantify the impact of confounding variables on patient's fasting experience such as accumulated thirst distress in patients undergoing repeated periods of fasting. Similarly, implementation of oral thirst interventions can also impact distress scores by significantly reducing thirst-related discomfort ${ }^{16}$

29. A controlled study to minimise the impact of these variables is likely to be beneficial in broadening the application of the VAS. 


\section{Conclusion}

The current study shows that the VAS is a valid and simple measure of thirst intensity and thirst distress, and sensitive in detecting a score difference based on fasting time. The VAS allows accurate and rapid assessment of thirst-related distress in fasting patients, which can be used to provide timely instigation of thirst interventions. Through the provision of objective data with regards to thirst distress, it is hoped that the VAS can be used in future research to provide insight into patient experience. Implementation of strategies to reduce fasting times to fit within current guidelines, should include patient-reported outcomes such as the VAS to improve patient care.

\section{References}

1. Lambert E, Carey S. Practice guideline recommendations on perioperative fasting: A systematic review. JPEN 2016;40(8):11581165. DOI: $10.1177 / 0148607114567713$.

2. Agency for Clinical Innovation (ACI). Key principles: Preoperative fasting in NSW public hospitals [Internet]. Sydney: ACl; 2016 [cited 2021 October 25]. Available from: www.aci.health.nsw.gov.au.

3. Lamb S, Close A, Bonnin C, Ferrie S. 'Nil by mouth' - Are we starving our patients? ePEN 2010;5(2):e90-e2.

4. Carey S, Hogan S. Failure in systems and culture: Barriers that prevent implementation of evidence-based fasting times for patients in the acute care setting JPEN 2020;45:933-940. DOI: 10.1002/jpen.1961.

5. Abola RE, Gan TJ. Preoperative fasting guidelines - why are we not following them? The time to act is now. Anesth Analg 2017;124(4):1041-1043. DOI: 10.1213/ ANE.0000000000001964.

6. Murphy GS, Ault ML, Wong HY, Szokol JW. The effect of a new NPO policy on operating room utilization. J Clin Anesth 2000;12(1):4851. DOI: 10.1016/s0952-8180(99)00139-7.

7. Liddle $\mathrm{C}$. Nil by mouth: Best practice patient education. Nurs Times 2014;110(26):12-14.

8. Carey SK, Conchin S, Bloomfield-Stone S. A qualitative study into the impact of fasting within a large tertiary hospital in Australia - the patients' perspective. J Clin Nurs 2015;24(13-14):1946-1954. DOI: 10.1111/ jocn.12847.
9. Diks J, van Hoorn DE, Nijveldt RJ, Boelens PG, Hofman Z, Bouritius H et al. Preoperative fasting: An outdated concept? JPEN 2005;29(4):298-304. DOI: $10.1177 / 0148607105029004298$.

10. Cheng J, Witney-Cochrane K, Cunich M, Ferrie S, Carey S. Defining and quantifying preventable and non-preventable hospitalacquired malnutrition: A cohort study. Nutr Diet 2019;76(5):620-627. DOI: 10.1111/17470080.12553 .

11. Bourke CD, Berkley JA, Prendergast AJ. Immune dysfunction as a cause and consequence of malnutrition. Trends Immunol 2016;37(6):386-398. DOI: 10.1016/j. it.2016.04.003.

12. Mosquera C, Koutlas NJ, Lee KC, Strickland A, Vohra NA, Zervos EE et al. Impact of malnutrition on gastrointestinal surgical patients. J Surg Res 2016;205(1):95-101. DOI: 10.1016/j.jss.2016.05.030.

13. Agarwal E, Ferguson M, Banks M, Batterham M, Bauer J, Capra S et al. Malnutrition and poor food intake are associated with prolonged hospital stay, frequent readmissions and greater in-hospital mortality: Results from the Nutrition Care Day Survey 2010. Clin Nutr 2012;32(5):737-745. DOI: 10.1016/j.clnu.2012.11.021.

14. Leib DE, Zimmerman CA, Knight ZA. Thirst. Curr Biol 2016;26(24):R1260-R1265. DOI: 10.1016/j.cub.2016.11.019.

15. Martins PR, Fonseca LF, Rossetto EG. Developing and validating the perioperative thirst discomfort scale. Rev Esc Enferm; 2017;51. DOI: 10.1590/S1980220X2016029003240.

16. Puntillo K, Arai SR, Cooper BA, Stotts NA Nelson JE. A randomized clinical trial of an intervention to relieve thirst and dry mouth in intensive care unit patients. Intensive Care Med 2014;40(9):1295-1302. DOI: 10.1007/ s00134-014-3339-z.

17. Reilly CM, Higgins M, Smith A, Culler $\mathrm{SD}$, Dunbar SB. Isolating the benefits of fluid restriction in patients with heart failure: A pilot study. Eur J Cardiovasc Nurs 2015;14(6):495-505. DOI: $10.1177 / 1474515114541729$.

18. Rothrock NE, Kaiser K, Cella D. Developing a valid patient-reported outcome measure. Clin Pharmacol Ther 2011;90(5):737-742. DOI: 10.1038/clpt.2011.195.

19. Weldring T, Smith SM. Patient-reported outcomes (PROs) and patient-reported outcome measures (PROMs). Health Serv Insights 2013;6:HSI. S11093. DOI: 10.4137/HSI. S11093.

20. Lohr KN, Zebrack BJ. Using patientreported outcomes in clinical practice: Challenges and opportunities. Qual Life Res 2009;18(1):99. DOI: 10.1007/s11136-008-9413-7.
21. Waleus N, Jaarsma T, van der Wal MHL, Kato P. Development and psychometric evaluation of the Thirst Distress Scale for patients with heart failure. Eur Cardiovasc Nurs 2018;17(3):226-34. DOI: $10.1177 / 1474515117728624$.

22. Kara B. Validity and reliability of the Turkish version of the thirst distress scale in patients on hemodialysis. Asian Nurs Res;2013;7(4):212-8. DOI: 10.1016/j. anr.2013.10.001.

23. Cheng LJ, Tan RL-Y, Luo N. Measurement Properties of the EQ VAS Around the Globe: A Systematic Review and Meta-Regression Analysis. Value Health 2021;24(8):1223-33. DOI: 10.1016/j.jval.2021.02.003.

24. Karcioglu O, Topacoglu H, Dikme O, Dikme O. A systematic review of the pain scales in adults: Which to use? Am J Emerg 2018;36(4):707-14. DOI: 10.1016/j. ajem.2018.01.008.

25. Kara B. Determinants of thirst distress in patients on hemodialysis. Int Urol Nephrol 2016;48(9):1525-32. DOI: 10.1016/j. ajem.2018.01.008.

26. Welch JL, Molzahn AE. Development of the thirst distress scale/commentary and response. Nephrol Nurs 2002;29(4):337.

27. Tosun B, Yava A, Açıkel C. Evaluating the effects of preoperative fasting and fluid limitation. Int J Nurs Pract 2015;21(2):156-165. DOI: $10.1111 /$ ijn.12239.

28. Voldby AW, Brandstrup B. Fluid therapy in the perioperative setting - a clinical review. J Intensive Care 2016;4(1):27. DOI: 10.1186/ s40560-016-0154-3.

29. Holte K, Kehlet H. Compensatory fluid administration for preoperative dehydration - does it improve outcome? Acta Anaesthesiol Scand 2002;46(9):10891093. DOI: $10.1034 / j .1399-6576.2002 .460906 . x$

30. Anker SD, Agewall S, Borggrefe M, Calvert M, Caro JJ, Cowie MR. The importance of patient-reported outcomes: A call for their comprehensive integration in cardiovascular clinical trials. Eur Heart J 2014;35(30):20012009. DOI: 10.1093/eurheartj/ehu205.

31. Kindler $\mathrm{CH}$, Harms $\mathrm{C}$, Amsler F, IhdeScholl T, Scheidegger D. The visual analog scale allows effective measurement of preoperative anxiety and detection of patients' anesthetic concerns. Anesth Analg 2000;90(3):706-712. DOI: 10.1097/00000539200003000-00036. 